\title{
A Class of Nothing
}

\section{Óscar Mascareñas}

Irish World Academy of Music and Dance, University of Limerick, Ireland.

\begin{abstract}
Imagine a class with no syllabus, no teacher, no instruction, no method, no homework, no assessments, no grades, no 'classroom'. What could that be? 'A Class of Nothing' is a radical pedagogical concept that stems from the need to create space. Physical space. Mental space. Space in time. Through the idea of nothing as a starting point, and no-instruction as a pedagogical tool, 'teacher' and 'student' immerse in a space of waiting, of disconnection from the outside world, and eventually, of discovery and making. In the space of 'A Class of Nothing' to educate means no more to teach, give, or exemplify: to lead out; but to inhabit, to experience: to let in. The concepts of teacher and student become blurred, and it is no longer possible to understand them in the traditional sense. Responses from students to various 'classes of nothing', reveal that this kind of experience is new, intriguing, mind boggling, unusual, surprising, interesting, strange; it places them in a different space: physically, mentally and in time. This paper introduces the notion of 'A Class of Nothing', and provides the reader with a number of examples where this concept and approach have been applied.
\end{abstract}

Keywords: Radical; Pedagogy; Nothingness; Nothing; Practice as Research; PaR. 


\section{Pre-liminary Thoughts}

Imagine a class with no syllabus, no teacher, no instruction, no method, no homework, no assessments, no grades, no 'classroom'. A class that does not start, and that does not end. A Class of Nothing. What could that be?

A Class of Nothing is a radical pedagogical concept that stems from the need to create space. Physical space. Mental space. Space in time. Students nowadays do not take time to do nothing, to be present, to share a space. We are too self absorbed, too focused on ourselves that rarely our actions form an uninterrupted continuum. Everything has to have a purpose. But we often forget that purpose does not always have to be pre-conceived or intentional. We expect too much, even though what is clear in this information-rich, virtual, digital era, is that it is never clear what to expect. We are constantly looking for satisfaction, to be satisfied by what we are shown or given. Being full of expectations limits possibility and somehow negates learning. If we expect nothing, we benefit from anything. We want to know, but often we do not really know exactly what. We want to understand, but end up confusing understanding with the processing or memorising of information. Everything now is information, but often we do not know what to do with it.

The new order of knowledge I propose as part of this Class of Nothing is not based on the processing or synthesising of information, but precisely on the non-intentional processing of what we observe. It is not about amounts or demonstrable outcomes, about how much we learn or not. Nothing is immeasurable. And so it is this new order of knowledge. You do not go to A Class of Nothing to learn about mathematical principles, or law, or engineering; although that could eventually take place. You go there precisely not to learn about that, but about what that is not. The new order of knowledge is in between the gaps of current understanding; and both permeate, inter-penetrate each other, although that is not always apparent. A Class of Nothing is an experience of possibility, discovery and clearance; not about pre-defined, factual outcomes. Clearance here is understood as the act of clearing from previous or existing technical knowledge. A clear space. A clearing. And the permission to discover and wonder. A Class of Nothing is about nothing in particular. Distractions are potential creative pathways. Distractions are welcome: they become a form of knowledge.

Nothing is not a precise thing. It is too big. Too big to see. Too big to feel. Too big to understand. It has no beginning and no end. It is pure space, unfathomable. Nothing is at the core of creativity, and one could argue that it is its principal instigator. Creativity stems from nothing, and ultimately leads to nothing. 


\section{An Experimental Approach}

Throughout my career as an artist and lecturer in music and contemporary arts practice in Ireland, I have come to the conclusion - through the careful observation and analysis of my teaching, and the overall student experience in both academic and practical modules - that students tend to do things in automatic, almost always aiming to fulfil the requirements of their course with little or no consideration for how all the learning they experience is actually applied in life. It is as if learning is just another one of those daily routines that they have to follow in order to go on with their own lives. This is a preoccupation I have had for a number of years; and after working on different ideas and methods, I came to realise that what students needed was Space. That led me to develop the concept of A Class of Nothing. If students took at least one hour per day as part of their curriculum to just be, to aim for nothing, perhaps to do nothing as well, then that Space would eventually emerge and manifest itself physically in space and time, and become enhanced creativity, new knowledge and new forms of learning, making and doing.

Learning and knowledge in the West have been historically associated with action and (intentional)-action-based processes. Proof of this is the present curricula in $1^{\text {st }}-, 2^{\text {nd }}$ - and $3^{\text {rd }}$-level education in Ireland (including $2^{\text {nd }}$ - and $3^{\text {rd }}$-level education in the arts) - and I would dare say in many other countries in Europe and beyond - which are mostly based on the acquisition and development of action-based knowledge through action-based learning, or the performance of intentional physical and/or mental (intellectual/rational) actions. In the case of the Western arts, artists such as Robert Rauschenberg (1951), John Cage (1952 and 1959), Yves Klein (1958), Gustav Metzger (1959), Mary Ellen Carroll (2006) and Marina Abramović (2014), amongst others, have employed the idea of nothing and the concept of nothingness as means to create art objects and experiences that develop from non-intentional action. This has changed the way we understand and perceive art: it has produced new ways of knowing. Similarly, A Class of Nothing aims to develop a new order of knowledge - one that is constructed through initial non-action and no-instruction which would produce an enhanced sense of awareness, and thus create new ways of understanding and interacting with the self and the world.

A Class of Nothing represents a good example of how arts practice research can inform, influence and inspire pedagogy, and how innovative pedagogical methods and practices may develop from an artistic idea. Since any artistic endeavour is, at the start, necessarily empirical and ephemeral in nature - as have been from the outset many of history's most respected scientific undertakings - any attempt to use theory to frame, inform or dialogue with what is being proposed here at this point may compromise its purpose, understanding and practical application - I specifically refer to theories that originate outside of the realm of the practice that is being outlined in this paper. 
Notwithstanding this, the paper and the practice itself are grounded in a series of longstanding works and approaches developed through history by artists, writers and philosophers. These works represent not only a point of departure for the ideas and examples presented and discussed here, but also a radical and inspirational reference that is both inherently theoretical and practical. In other words, the works referred to here are indeed theory, just not of the same nature and form as that found in more traditional pedagogical writings and related academic undertakings.

\subsection{First experiment: Aldeburgh Music}

The first time I experimented with the concept of A Class of Nothing was in the summer of 2015, during an artistic residency at Aldeburgh Music, in Snape, England. I did so with a group of about 25 of the most talented and promising young musicians of the UK, aged 11 to 19 . I did not know what to expect. I did not have a clear idea of what I was doing or where I was going with it. All I said to the students was that it was 'a class of nothing', and that we were going to wait for an hour and see what happened. And so we waited, doing nothing in particular. Some were seated, some standing. There were no rules whatsoever. Everyone was free to just be, in that moment, together, without expectations of any kind.

Then, out of nothing, one of my colleagues - who was there to teach during the residency threw a ball on the floor that he had made with a piece of paper. He did it gently, but intentionally, as if aiming at a 'non-existent bin'. And that was 'all that was needed'. It created a storm of activity of all kinds. How one thing developed into another, I cannot recall, nor do I think it was entirely clear. It simply went from apparent non-action to full activity. Noises here and there, running all over the place, shouting, people talking to themselves and to others, laughter - some nervous, some simply out of joy or some unidentified impulse - collaborative music making, improvisation, reading/sounding of texts, dancing, walking, pianos, violins, guitars, drums, oboes, clarinets, harps, flutes, voices: all sort of instruments being banged, played, used as devices to create meta-sonic stuff. It was a deliciously and carefully-constructed chaos. A chaos that emerged out of nothing. Out of non-activity. Out of many things.

This first experiment was successful in as much as it was about nothing. And it was succesful because it rapidly became a source of creativity of the most indescribable kind. It was art in different manifestations: music, dance, theatre, festival, poetry; but with undefined boundaries. It was learning and knowledge of a new order. It remains in my memory as one of the most bizarre, yet unforgettable teaching experiences I have ever had. A true and radical pedagogical experiment. 


\subsection{A second experiment: Coventry University}

As part of an ERASMUS exchange between the University of Limerick in Ireland, where I work, and Coventry University, in the UK, I was invited in 2016 to lead a residency in the latter's Department of Music. One of the sessions I was to have was with the music education students. The opportunity could not have been more suitable. I decided to do $A$ Class of Nothing with them. For this, I prepared a written poetic reflection that I was going to read once the students had entered the space (classroom/performance space). This was going to be accompanied by projections of different art works connected with nothing and nothingness: works by Robert Rauschenberg (1951), Yves Klein (1958) and Gustav Metzger (1959) were shown.

The class entered and gathered on the floor. I had previously asked their teacher to sit with them and just 'do nothing'. For a period of time the students were chatting about different topics. Some were aware of my presence, and the presence of the work being projected on the screen. The chatter continued for a while until it eventually died out slowly. I waited. Then I proceeded to read as if I were on my own in the room. This created a sense of intrigue and confusion to a certain extent. Once I finished the reflection I had written for the occasion, I waited. After some time passed, I went towards the door, and on my way to it I banged a few notes on a piano that was nearby. I went out, said hello to a lady that was doing some cleaning, and went back in again. Nothing much happened. It was contrastingly different to the experience in Aldeburgh, but no less successful. It had achieved what I had aimed at: nothing; and as a consequence, a great deal of something.

Later, I sat with the students and their teacher, and - after some silence - I started to ask questions about the experience. The discussion that ensued was very rich and inspiring, full of insight and reflection. This is what the teacher wrote about it afterwards:

A very thought-provoking class. From confusion and uncertainty, the group blossomed slowly but surely into a collegiate collective, open-mindedly discovering and learning from a starting point of nothing. This reframed the initial feelings into material for self-awareness and reflection on the ethics of teaching and learning, indeed of society itself. This was a radical pedagogy, ideal for a module in music education. Óscar facilitated with a mixture of poetry, visuals, performance and pedagogical skill - starting with nothing, rather than instruction, and ending (but not really ending...) with a sense of possibility and empowerment, rather than a purely technical outcome. (Habron 2016)

Both the experiences in Aldeburgh Music and Coventry University gave me the insight, strength and confidence to continue developing the concept of A Class of Nothing, and to continue experimenting with it in different situations and contexts. These are summarised in the next section. 


\section{Further Presentations and Experiments}

In April 2016 I had the opportunity to present the concept of A Class of Nothing at the Artsin-Education National Day in the Irish Museum of Modern Art in Dublin. This was organised by the Arts in Education Portal, which is 'the key national digital resource of arts in education practice in Ireland...launched in May 2015 as an initiative of the Department of Education and Skills and the Department of Culture, Heritage and the Gaeltacht' www.artsineducation.ie. I created a performance art-like experience for those who attended my 'talk', and read and performed from a reflection I wrote for the occasion. I also showed images similar to those I used during the session in Coventry University. The public attending consisted mostly of educators and people interested in the field of pedagogy. There were also artists and gallery curators present during the talk. The questions, reactions and subsequent discussion left me feeling very positive and stimulated, which showed that the concept was strong and worth exploring further.

I have also offered A Class of Nothing to students of Irish Dance and Voice and Dance at the Irish World Academy of Music and Dance in the University of Limerick. For one of the occasions (with the latter group), I created a set of 10 'rules' (which I titled 'Rules (some)'). I read these rules at the start of the class and then told to the students that I was not going to say anything else. The rules were: 1. Talk to yourself; 2 . Don't talk to others (unless you need to say nothing); 3. Come and go as you please or need; 4. Do as much or as little as you want or need; 5. Don't fall asleep (try); 6. Don't zone out (try); 7. Be patient; 8. If you have any questions, don't ask (unless you know); 9. I'm not here to answer questions - like you, I'm here to formulate them, and try them out; 10. Don't waste time.

Like the very first experience of the Class of Nothing in Aldeburgh Music, the class was full of everything: noises, talking, singing, dancing, shouting, people leaving the classroom and coming back, people sitting and doing little or nothing, people watching, waiting, in silence. Interaction. Contemplation. Nothing.

Once more, this class was a success in as much as nothing in particular was accomplished. Nothing: a lot of things too. New learning, new understandings. A great number of interesting and stimulating questions emerged after the class (as I normally dedicate a considerable amount of time in each class to discuss what happened). It helped the students question things they never questioned before, or that they took for granted. The very concepts of nothing and nothingness were seen and understood from different and fresh perspectives. Here are some of the thoughts the students shared in their journals (their identities have been kept anonymous for ethical reasons):

This class was very mind boggling. In a way it felt that everything that I was doing was right and wrong at the same time...[A]s the class went on it was apparent that nothing meant different things to everyone. (Student 1) 
This was by far the most unusual thing I've had to do thus far. Uncertain of its actual outcome. I worked on different ways to do "nothing"...Soon enough the harder I tried the more I realized I was actually doing "something”. (Student 2)

After some classes I was encouraged to question my perspective of different things for instance, the "class of nothing"...I have begun to wonder is there such a thing as "nothing" or is it just a word and actually non-existent. (Student 3)

When we had the class of "nothing", I didn't know how to react...Everyone around me is in their own world, all going mad!...From this class I noticed how much I overthink things, perhaps if we were to do this class all over again I would do it very different and do my best not to think and just let the class flow. (Student 4)

We were given the rules and then it was up to us - to do nothing and something...I felt so strange. Rarely are we asked to sit and do what one wants to do...I think my mind went into shock at being told it was a class of nothing and instantly one feels that something should be done! At one point, people started to move and then sounds and comments were emitted from people who were straddled all around the room...The 'class of nothing' had changed into 'everything' as everything happened...It was a very strange afternoon but intriguing... (Student 5)

It was something that we had never experienced before and I believe that it made me see a varying perspective into the world of improvisation... (Student 6)

Overall, I found it incredibly difficult to do nothing. I found that I was constantly fidgeting for no reason. (Student 7)

It was strange because this class went against all the classroom rules that we have grown up with since childhood...I think that I was nervous to explore outside of the norm. (Student 8)

Some people just assumed that talking was not allowed and were suprized then when [one student] broke the silence and Oscar responded by laughing, this made laughter okay in the class of nothing, so the laughter continued...there are unknown limitations, you never know what will happen. In a class of nothing there is no negative or positive, things just simply are. (Student 9)

I found it strange as I presumed, we were supposed to be sitting there in silence and listening to our thoughts. Why did I presume this? When other people began to speak/sing their thoughts aloud it encouraged me to then speak. Although I could have stayed in silence for the full process. (Student 10) 


\section{Conclusions}

What is evident from the students' words above, and from the reactions and feedback received during other classes of nothing, is not only that this kind of experience is new, intriguing, mind boggling, unusual, surprising, interesting, strange; but that it places them in a different space: physically, mentally and in time; and this translation from being in a classical classroom situation - with all the rituals and behaviours that that entails - to being in a space of nothing, an open space, a space of possibility and play, enables them to not only view things differently, but to question what that they do in a classroom (and not), what they learn (and not), what the usefulness of it all is, what it means to be creative, to wait, to do nothing, to be in a space of nothing, to be part of that nothingness. Although this concept has been so far applied within the performing arts education sector at 3rd level, the approach could be implemented at all levels and in all disciplines. It could eventually be extended to other learning media, such as online and/or blended education, although it is important to highlight the performative nature of the concept.

No matter the responses or reactions one may have to this proposal, what is clear from the observations reported here, is that the radicalness at its core displaces, pushes, enables, overflows. It also creates something. Something new. Something vast: rich and barren. And nothing, too. After A Class of Nothing, nothing is never going to be the same. The same nothing. Never nothing ever absent. Never fully present. For when nothing is expected, we benefit from everything. In the words of Samuel Beckett (1954), 'Nothing to be done', and in those of Lao Tzu, 'When nothing is done, nothing is left undone'.

\section{References}

Abramović, M. (2014). 512 Hours. London: Serpentine Gallery.

BA Voice and Dance Student Journals (2018). Submitted as part of the students' course work at the Irish World Academy of Music and Dance in the University of Limerick.

Beckett, S. (1954). [En attendant Godot.] Waiting for Godot. Tragicomedy (Translated from his original French text by the author.) [With illustrations, including a portrait.]. New York: Grove Press.

Cage, J. (1952). 4' 33”. UK: Edition Peters

Cage, J. (1959). Lecture on Nothing. Incontri Musicali. Milano: Edizioni Suvini Zerboni.

Carroll, M., E. (2006). Nothing. Ostende, Argentina: The Foundation Telefónica.

Habron, J. (2016). Private correspondence.

Klein, Y. (1958). Le Vide. Paris: The Iris Clert Gallery.

Lao Tzu (attributed to) (6th c. to 4th c. BC). Tao Te Ching. Chapter 48.

Metzger, G. (1959). Manifesto for an Auto-Destructive Art. London.

Rauschenberg, R. (1951). The White Paintings. New York: Robert Rauschenberg Foundation. 